\title{
Prediction of the developmental potential of hamster embryos in vitro by precise timing of the third cell cycle
}

\author{
D. S. Gonzales ${ }^{1}$, J. C. Pinheiro ${ }^{2}$ and B. D. Bavister ${ }^{1 *}$ \\ ${ }^{1}$ Department of Animal Health and Biomedical Sciences; and ${ }^{2}$ Department of Biostatistics, \\ University of Wisconsin, Madison, Wisconsin 53706, USA
}

\begin{abstract}
Time-lapse videomicrography was used to determine the timing of early developmental events in hamster embryos in vitro. The time intervals from pronuclear envelope breakdown to the completion of the first cleavage $\left(\mathrm{Dt} t_{2}\right)$, second cleavage $\left(\mathrm{Dt}_{4}=2-4\right.$ cells), third cleavage ( $\mathrm{Dt} t_{8}=4-8$ cells), blastocyst formation, and zona escape were precisely measured to determine whether the variable 'time' $(t)$ can be used to predict the developmental potential of preimplantation embryos. The range of the developmental time interval (Dt) from the second to the third cleavage divisions $\left(\mathrm{D} t_{8}\right)$ provided the best indicator for predicting the probabilities of blastocyst formation and zona escape $(P=0.015$ and 0.041 , respectively). $\mathrm{D} t_{8}$ was subdivided into consecutive time cutoff points of $\leq 750, \leq 800$, $\leq 850$ and $\leq 900 \mathrm{~min}$. Of the embryos that took $\leq 750 \mathrm{~min}$ to complete the third cleavage division, $92 \%$ developed into blastocysts and $69 \%$ escaped from their zonae pellucidae. When the completion of $\mathrm{D} t_{8}$ extended to $\leq 900 \mathrm{~min}$, the percentages decreased to $75 \%$ and $49 \%$ for blastocyst formation and zona escape, respectively. This study identifies a specific developmental time interval and a model whereby time can be used as a noninvasive parameter to predict embryo developmental potential in vitro.
\end{abstract}

\section{Introduction}

Culture of fertilized eggs or embryos at the early cleavage stage retards their further development, and can reduce or even destroy embryo viability (Bowman and McLaren, 1970; Harlow and Quinn, 1982; Sakkas et al., 1989; Van Soom et al., 1992; Barnett and Bavister, 1992; McKiernan and Bavister, 1994; Gonzales and Bavister, 1995). Frequently, embryos cultured in vitro arrest before the blastocyst stage or fail to escape from their zonae pellucidae (Maurer et al., 1970; Fishel et al, 1985; Bavister, 1988a; Lindenberg and Hyttel, 1989; Lopata and Hay, 1989; McKiernan and Bavister, 1990; Kishi et al., 1991; Gonzales and Bavister, 1995). These problems not only provide incentives for devising improved culture media (Bavister, 1995) but also necessitate methods for selecting the most competent and viable embryos for transfer to recipients in both animal and human programmes. The high frequency of embryonic loss after transfer in human IVF clinics (Amso and Shaw, 1993) has also stimulated the search for a noninvasive tool to assess embryo viability and potential for subsequent transfer.

Several parameters have been used to assess the quality of preimplantation embryos. Most methods involve use of morphological criteria (Lindner and Wright, 1983; McKinnon and Squires, 1988; Wolf, 1988; Bernardini et al., 1993; Tasdemir et al., 1993), or biochemical procedures (Leese et al., 1986; Gardner and Leese, 1993) that may or may not be compatible

${ }^{*}$ Correspondence

Received 28 February 1995. with continued development or successful embryo transfer (Conaghan et al., 1993; Bavister, 1995; Barnett and Bavister, in press). The variability of biochemical measurements (for example uptake of pyruvate or glucose) among embryos and at different stages of development diminishes the value of this approach for selecting the most competent embryos (Leese et al., 1986; Conaghan et al., 1993). Fluorescein diacetate has been used for evaluating embryos (Mohr and Trounson, 1980; Hutz et al., 1985; Noto et al., 1991) but requires expensive equipment, is invasive and may not correlate with embryo viability (Hoppe and Bavister, 1984). Use of subjective morphological criteria has not improved the frequency (which is approximately $10 \%$ for individual human embryos) of implantation and subsequent development through gestation (Edwards, 1986; Rogers et al., 1986; Bolton et al., 1989; Van Blerkom, 1989; Amso and Shaw, 1993). Although the success rate of embryo transfer improved in cattle up to the 1980s, there has been little improvement during the last 10-1.5 years in the commercial success rate (which is $50-70 \%$ of transferred embryos, depending on stage and morphological criteria; Hasler et al., 1987; Hasler, 1992). Therefore, morphological assessment is not very effective for separating embryos with high versus low potential for further development and there remains a need for improvement in domestic species.

Developmental endpoints used in conventional experimental protocols, such as the proportion of embryos reaching morulae or blastocysts, give information that does not directly indicate embryonic potential or viability (Angell et al., 1987) and can even be misleading about the efficacy of culture protocols (Bavister, 1995). Determination of the mean number of cells, 
especially with a differential cell count (inner cell mass versus trophectoderm; Handyside and Hunter, 1984), can be very informative but present methods for this destroy the embryo.

An alternative to using proportions of embryos developing into blastocysts after a predetermined culture period is to measure the time taken for development to different stages. The rationale for using time as an indicator of developmental competence stems from observations that embryos that develop faster in culture have a greater potential to reach the morula and blastocyst stages than do those that develop more slowly (Bavister et al, 1983a; Plante and King, 1992; Van Soom et al., 1992; McKiernan and Bavister, 1994; Grisart et al., 1994). In addition, cultured bovine embryos reaching the blastocyst stage on days 6-8 implant at higher rates than do day 9 blastocysts after transfer (Hasler et al., 1987, 1995). However, timing data from most studies are derived from infrequent examination of embryos in culture (usually not more than once every 12 or $24 \mathrm{~h}$ ). Substantial differences among embryos can occur in the timing of cleavage events, and these may be missed if examinations are infrequent, possibly misdirecting the selection of embryos for transfer (Bavister, 1995). The timing of early cleavage events may be critical for assessing cultured embryos, since development is often delayed in vitro (Grisart et al., 1994; Gonzales and Bavister, 1995). Moreover, measurement of developmental timing has the advantage of being noninvasive.

Using time-lapse videomicrography of cultured hamster embryos, we set out to test the hypothesis that the precise timing of early cleavages can predict the developmental potential of embryos. The aim was to validate a model for selecting embryos with a high probability of success (success being defined as either reaching the blastocyst stage or escaping the zona pellucida), thereby providing a noninvasive means to select embryos with a greater likelihood of further development and pregnancy after embryo transfer.

\section{Materials and Methods}

\section{Animals}

Female golden hamsters used in this study were sexually mature (3-4 months old, mass $110-130 \mathrm{~g}$ ) and naturally cyclic (i.e., not gonadotrophin-stimulated). Animals were maintained under a photoperiod of $14 \mathrm{~h}$ light:10 h dark (lights on at 06:00 h and off at 20:00 h central standard time; CST). Females were mated on day 4 , the evening of the oestrous vaginal discharge (Orsini, 1961; Bavister, 1989) at 18:30 h CST to proven fertile males. Consistent timing in the experimental protocol was controlled by excluding from the study females that did not mate within 15 min after placement with males. Five mated female hamsters were used in this timing study and three in the control group.

\section{Collection and culture of embryos}

One-cell embryos were flushed from the oviducts the day after mating (day 1 ) at 16:30 h CST, approximately $12.5 \mathrm{~h}$ after egg activation (Orsini, 1961; Bavister et al., 1983b) with hamster embryo culture medium-4m (HECM-4m; Gonzales and
Bavister, 1995). Egg activation is defined as the time when a spermatozoon penetrates the egg; in this case at approximately 04:00 h on day 1 (Bavister $e$ al., 1983b). Each culture consisted of the embryos from a single female and embryos were placed in $60 \mathrm{~mm} \times 50 \mathrm{~mm}$ Falcon Petri dishes (Becton Dickinson and Co., Lincoln Park, NJ) containing $80 \mu \mathrm{l}$ drops of HECM-4m overlaid with silicone oil. Culture drops were kept at $37^{\circ} \mathrm{C}$, $10 \% \mathrm{CO}_{2}$ and $5 \% \mathrm{O}_{2}$ in an incubator for a minimum of $2 \mathrm{~h}$ before embryo collection. There were five replicate time-lapse cultures, because only one culture could be monitored at a time with the equipment available. There were 10, 10, 19, 13 and 10 embryos, respectively, in cultures one to five.

Each embryo provided complete timing data for the duration of the culture, providing a total of $n=62$ discrete data sets. Embryos were cultured either in a standard incubator or on the stage of a Nikon Diaphot inverted microscope (Nikon Corp., Tokyo). The microscope was equipped with an environment control chamber surrounding the optics and the stage. Within the chamber, a controlled, humidified atmosphere of $10 \% \mathrm{CO}_{2}$, $5 \% \mathrm{O}_{2}$ and $85 \% \mathrm{~N}_{2}$ at $37^{\circ} \mathrm{C}$ was maintained. Embryos were cultured until they either escaped their zonae or began to degenerate (5-7 days in culture). The microscope light source was covered with an orange-red filter to protect the embryos from light toxicity (Umaoka et al., 1993).

\section{Time-lapse data collection}

Details of the system used in this study for culturing embryos on the microscope stage and for data collection by time-lapse videomicrography were described by Bavister (1988b) and Gonzales and Bavister (1995). Briefly, embryo cultures were monitored under Nomarski DIC (Nikon) optics with a $\times 10$ objective, and recorded using a video camera fitted with a Newvicon detector tube (Series 70; Dage-MTI Inc., Michigan City, IN) and a Panasonic Super-VHS recorder (S-VHS, AG-6720A; Panasonic, Secaucus, NJ). A zoom lens fitted between the microscope port and the detector tube was set at $\times 1.0$ or $\times 1.5$ to obtain magnifications of $\times 10$ or $\times 15$. At these magnifications, the male and female pronuclei of the zygotes were easily observed at the initiation of culture (12-13 h after egg activation; Fig. 1). Timing was initiated $(t=0)$ at pronuclear envelope breakdown for each embryo (Figs 1 and 2). The timing of developmental events such as cleavage, blastocoel formation and zona escape was determined separately for each embryo.

Time-lapse videos were recorded at 1/120 normal rate, so that $\mathrm{I} \mathrm{h}$ of development was compressed into $30 \mathrm{~s}$ of real time. Precise temporal information on development was obtained from the time/date generator of the S-VHS recorder. The first developmental interval was the time from pronuclear envelope breakdown to the completion of the first cleavage division $\left(\mathrm{Dt} t_{2}\right.$; i.e., $\mathrm{AB}$ to $\mathrm{A}+\mathrm{B}$; Fig. 2). The second interval ( $\mathrm{Dt}_{4} ;$ Fig. 2 ) began at the completion of the first cleavage division and extended to the completion of the second cleavage division (from two to four cells; i.e., $B$ to $B_{1}+B_{2}$ ). The time interval from four to eight cells $\left(\mathrm{Dt}_{g}\right)$ began with the completion of the second cleavage division and ended with the completion of cytokinesis of blastomere $\mathrm{B}_{2}$ (i.e., $\mathrm{B}_{2}$ to $\mathrm{B}_{2 \alpha}+\mathrm{B}_{2 \beta} ;$ Fig. 2). It was not possible to determine the timing of cleavages past the third Downloaded from Bioscientifica.com at 04/26/2023 12:24:19PM 


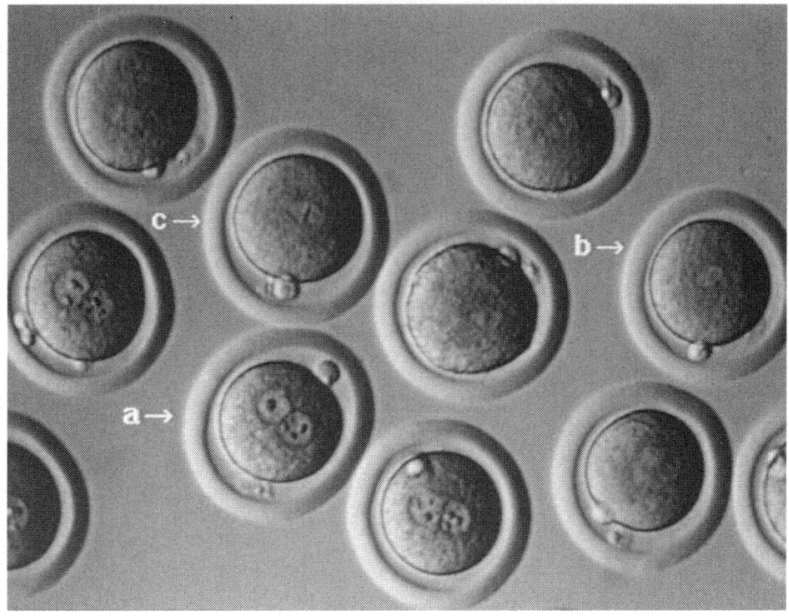

Fig. 1. Computer-generated digital image of pronucleate hamster embryos (a), with some undergoing pronuclear envelope breakdown (b) and spindle pole formation (c).

cleavage division because of the decreasing size of individual blastomeres, the progressively obscured view by the increasing number of blastomeres, and the increasing cell-cell adhesion as a result of morula formation. The time of blastocyst formation was established as the time when a blastocoel was first apparent in the plane of focus. Zona escape was discerned when a focal area of dissolution penetrated the complete thickness of the zona wall (Gonzales and Bavister, 1995).

Digital images were generated for analysis and for publication. A detailed description of computer generated digital imaging of cultured embryos is given by Gonzales and Bavister (1995). Briefly, at fixed intervals (5, 10 or $20 \mathrm{~min}$ ), eight digital video images were collected by a personal computer (486/ $33 \mathrm{MHz}$; Gateway 2000, Sioux City, SD). The eight digital images were averaged and the averaged image was stored in the computer for analysis and photography. This process used the computer as a time-lapse device that gathered static data over time. Images for publication (Fig. 1) were made by photographing the screen of the video monitor with a Nikon $\mathrm{N}-2000$ camera, using a $55 \mathrm{~mm}$ macro lens and TMAX 400 film (Eastman Kodak Co., Rochester, NY).

\section{Experimental design}

Experiment 1: control experiment. Three replicate experiments using three female hamsters (replication over days) were conducted $(n=34)$ to determine whether there was a difference in the development of videotaped embryos (cultured under continuous red light) compared with embryos cultured in the incubator (absence of light; Umaoka et al., 1993). These three replicates were run at the same time as the first three replicates in Expt 2 and consisted of one-cell embryos cultured in an incubator (model 3187, Forma Scientific, Marietta, $\mathrm{OH}$ ) under the same temperature and gas conditions as on the microscope stage but in the absence of light. Embryos were collected and placed in culture, as described above, for the timing of embryo development.
Experiment 2: timing of embryo development. Five replicates were conducted (five female hamsters over days), with each culture initiated at the same time after egg activation. The timing data of early developmental events were collectively and individually analysed using logistic regression analysis, to determine whether time could be used as a tool for predicting embryo development potential in vitro. To detect differences in the five cultures, comparisons were made by ANOVA (Snedecor and Cochran, 1989) of the mean times of early cleavage events, blastocyst formation and zona escape.

Embryos in Expt 1 (control group) and Expt 2 (timing group) were assessed after $48 \mathrm{~h}$ and $72 \mathrm{~h}$ of culture for the percentages of eight cells and blastocysts, respectively. These results were compared using Student's $t$ test (Snedecor and Cochran, 1989).

\section{Statistical model for predicting developmental potential}

Logistic regression (Agresti, 1990) was used to estimate the probability of blastocyst formation and of zona escape as a function of time, during early cleavages in preimplantation embryo development. Three different time intervals $\left(\mathrm{D} t_{2}, \mathrm{D} t_{4}\right.$ and $\mathrm{Dt}_{8}$ ) were examined separately and in all combinations in the analysis. The logistic model for the probability $(P)$ of blastocyst formation as a function of the variable time $(t)$ is written as:

$$
P(\text { blastocyst } \mid t)=\frac{e^{(u+\beta t)}}{I+e^{(u+\beta t)}}
$$

where the parameter $\beta$ determines the association between $t$ and $P$ (Agresti, 1990). In this model, if $\beta<0$, the probability decreases with $t$; if $\beta>0$ the probability increases with $t$; and if $\beta=0$, the probability does not depend on $t$. Therefore, the parameter $\beta$ establishes the dependence between the probability and time. A property of the logistic model is that it can be easily linearized. The log odds ratio (Agresti, 1990) of $P_{t}=P($ blastocyst $\mid t)$ in the logistic model is a linear function of $t$ and is written as $\log \left(P_{t} / 1-P_{t}\right)=(\alpha+\beta t)$. The parameter $\alpha$ is the $y$ intercept and the parameter $\beta$ is the slope of the log odds ratio. The time interval with a significant $P$ value $(P=0.05)$ for the null hypothesis that $\beta=0$ can be used to predict developmental potential. A similar model was used for the probability of zona escape.

\section{Practical application of the model}

In the developmental interval that was best able to predict blastocyst formation and zona escape, time cutoff points were made to compare success rates as a function of time. The percentages of embryos that became blastocysts and escaped their zonae after completing the third cleavage division within the designated time cutoff points were calculated. The time cutoff points were determined following logistic regression analysis.

\section{Results}

\section{Experiment 1 (control group)}

There were no significant differences in the numbers of eight-cell embryos and blastocysts between the control group Downloaded from Bioscientifica.com at 04/26/2023 12:24:19PM 


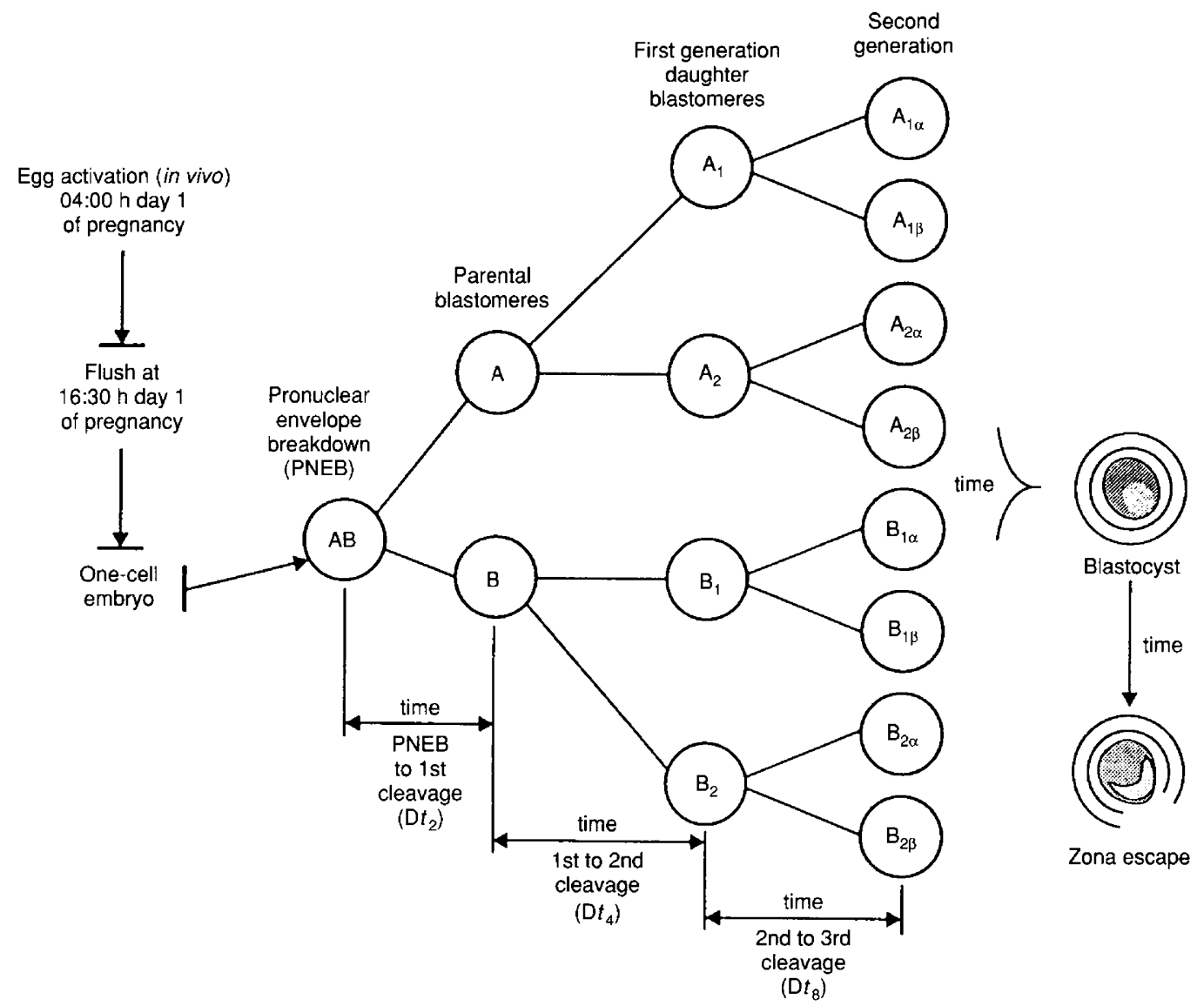

Fig. 2. Schematic of hamster embryo generation time in vitro. Circles enclosing cleavage notations represent individual blastomeres. The time intervals designated between arrows $\left(\mathrm{D} t_{2}, \mathrm{Dt} t_{4}\right.$ and $\left.\mathrm{D} t_{8}\right)$ were tested by logistic regression analysis.

(Expt 1) and the 'timing' group (Expt 2) at $48 \mathrm{~h}$ and $72 \mathrm{~h}$, respectively $(P>0.1$ for both observation times). After $72 \mathrm{~h}$ of culture, $70.6 \%$ of the embryos in the control group had reached the blastocyst stage.

\section{Experiment 2 (timing group)}

No significant differences were found among the five replicate cultures in the mean times of early cleavage events, blastocyst formation and zona escape; therefore, the data were pooled (Table 1). The percentages of blastocyst formation and zona escape were $68 \%$ and $45 \%$, respectively. By logistic regression analysis, the developmental intervals $\mathrm{D} t_{2}$ and $\mathrm{Dt} t_{4}$ (Fig. 2) had $P$ values that were not significant for predicting blastocyst formation and zona escape (Table 2). The predictive value of the combined intervals $\left(\mathrm{D} t_{2}+\mathrm{D} t_{4}\right)$ was also not significant. The developmental time interval that best predicted blastocyst formation and zona escape was $\mathrm{D} t_{8}$ (Table 2). As the developmental interval $\mathrm{D} t_{8}$ increased, the estimated probabilities of blastocyst formation and of zona escape decreased (Fig. 3); the estimated $95 \%$ confidence intervals for the probabilities are also represented. Table 3 provides the estimates of the parameters $\alpha$ and $\beta$ and their standard errors for the developmental interval $\mathrm{D} t_{8}$. Both estimates of $\beta$ are negative
Table 1. Time intervals of development events in preimplantation hamster embryos in vitro ${ }^{a}$

\begin{tabular}{lrrc}
\hline Event & & $\begin{array}{c}\text { Mean elapsed } \\
\text { time } \pm \mathrm{SEM}(\mathrm{h})\end{array}$ & $\begin{array}{c}\text { Range } \\
(\mathrm{h})\end{array}$ \\
\hline PNEB $^{\text {d }}$ to first cleavage $\left(\mathrm{Dt} t_{2}\right)$ & 62 & $1.4 \pm 0.1$ & $0.5-2.4$ \\
First to second cleavage $\left(\mathrm{Dt}_{4}\right)$ & 62 & $28.1 \pm 0.2$ & $25.1-36.8$ \\
Second to third cleavage $\left(\mathrm{D} t_{8}\right)$ & 62 & $11.9 \pm 0.1$ & $9.8-26.5$ \\
PNEB to blastocyst & 42 & $61.7 \pm 1.1$ & $53.4-83.9$ \\
PNEB to zona escape & 28 & $88.82 \pm 2.0$ & $78.2-105.3$
\end{tabular}

${ }^{a}$ Embryos were flushed from the oviducts of five female hamsters at $16: 30 \mathrm{~h}$ on day 1 of pregnancy.

${ }^{b}$ Described in Fig. 2.

'Number of observations (= number of embryos).

"Pronuclear envelope breakdown, from which timing was initiated for each embryo.

for $\mathrm{D} t_{8}$, indicating that the probability of blastocyst formation and zona escape decreases with $t$. The concordance, which provides a measure of fit in logistic regression analysis (Agresti, 1990), was $74.2 \%$ for blastocyst formation and $61.2 \%$ for zona escape. 
Table 2. $P$ values for the developmental intervals tested by logistic regression analysis

\begin{tabular}{lcc}
\hline Developmental time interval & $\begin{array}{l}\text { P value for } \\
\text { blastocyst } \\
\text { formation }\end{array}$ & $\begin{array}{c}P \text { value for } \\
\text { zona escape }\end{array}$ \\
\hline PNEB ${ }^{\text {a }}$ to first cleavage (Dt $)$ & 0.214 & 0.075 \\
First to second cleavage $\left(\mathrm{Dt} t_{4}\right)$ & 0.288 & 0.585 \\
Second to third cleavage $\left(\mathrm{Dt} t_{8}\right)^{\mathrm{b}}$ & 0.015 & 0.041 \\
\end{tabular}

aPronuclear envelope breakdown.

${ }^{\text {bOnly }} \mathrm{D} t_{8}$ provided significant $P$ values for estimating the probability of reaching the endpoint shown.
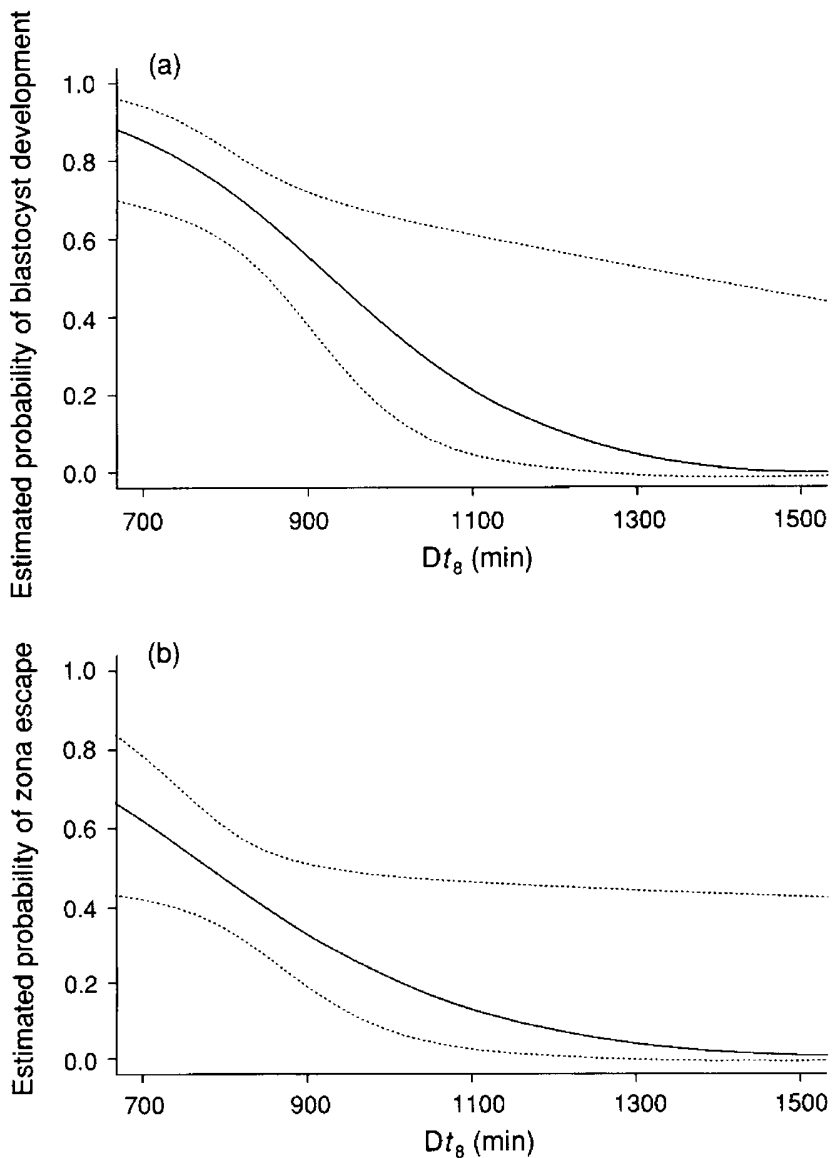

Fig. 3. Logistic regression analysis of (a) probability of blastocyst formation and (b) probability of zona escape in hamster embryos cultured in vitro. Time on the $x$ axis is elapsed time during the developmental interval $\mathrm{Dt}_{8}$. The $P$ values of the estimated parameter $\beta$ of the fitted lines ( $\longrightarrow$ ) for (a) blastocyst formation and (b) zona escape are shown in Table $2 ;(\cdots)$ represents the plot of the $95 \%$ pointwise confidence limits for the estimated probabilities in logistic regression analysis.

\section{Empirical evidence for using time as a variable in the model}

The time interval of 725-900 min within $D t_{g}$ represents the time when most of the embryos (71\% of total observations) completed the third cleavage division (Fig. 4). Another $11 \%$ of
Table 3. Estimated parameters for $\mathrm{D} t_{8}$ in the logistic regression model

\begin{tabular}{lcc}
\hline Response $^{\mathrm{a}}$ & $\alpha$ (SEM) & $\beta(\mathrm{SEM})$ \\
\hline Blastocyst formation $^{\mathrm{b}}$ & $7.13(2.63)$ & $-0.008(0.003)$ \\
Zona escape $^{\mathrm{b}}$ & $4.68(2.37)$ & $-0.006(0.003)$
\end{tabular}

Tatal number of embryos (observations) $=62$.

${ }^{b}$ Concordance (success of predictions) $=74.2 \%$ for blastocyst formation and $61.2 \%$ for zona escape.
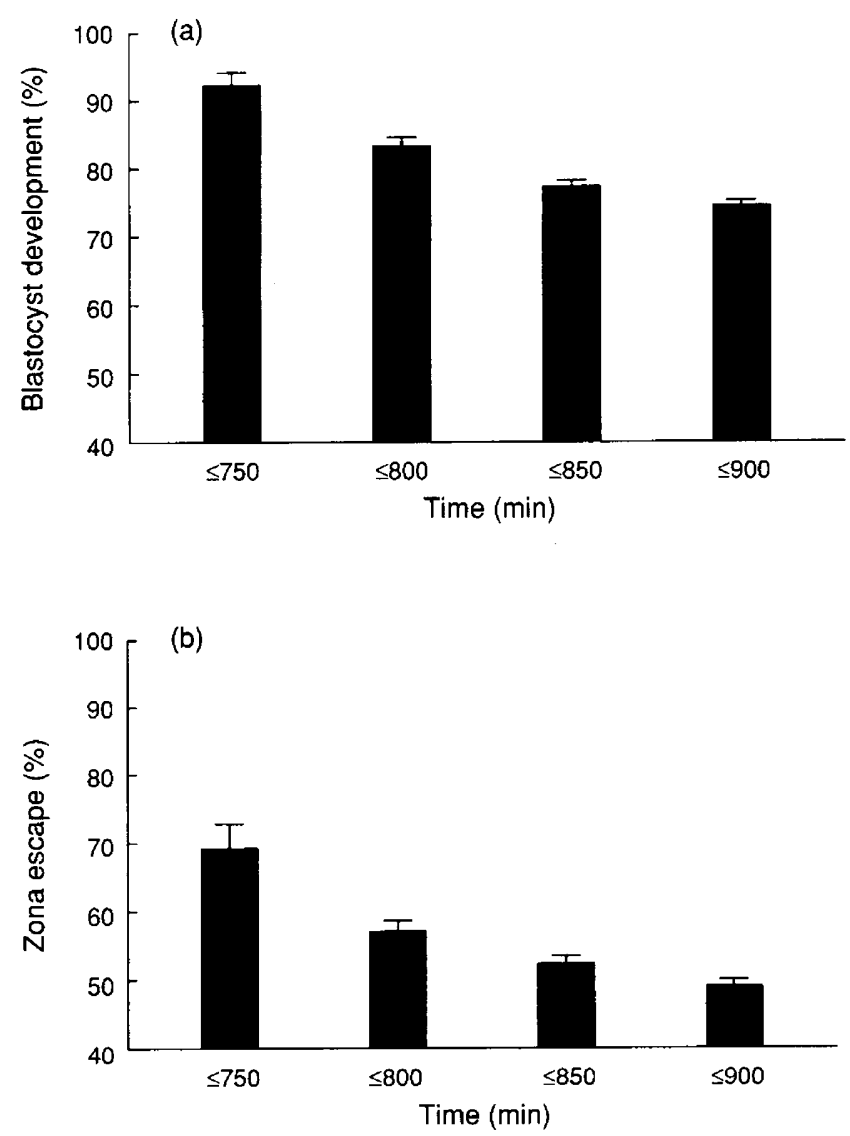

Fig. 4. Observed incidence of (a) blastocyst formation and (b) zona escape in $50 \mathrm{~min}$ subsets during the developmental interval $\mathrm{Dt}_{8}$ in hamster embryos cultured in vitro. The $x$ axis is elapsed time during $\mathrm{D} t_{8}$. The time points were chosen based on the logistic regression model. Within (a) and (b), each response is significantly different from all other time cutoff points $(P \leqslant 0.002$ and $P \leqslant 0.03$, respectively). Within the time cutoffs for completion of $\mathrm{Dt}_{8}, \leq 750, \leq 800, \leq 850$ and $\leq 900 \mathrm{~min}$, the proportions of embryos (percentage of total, inclusive values) were $21,48,71$ and $82 \%$, respectively, and the numbers (inclusive) of embryos within each cutoff were 13,30, 44 and 51 , respectively.

the embryos completed the third cleavage division before $725 \mathrm{~min}$, and the remaining $18 \%$ after $900 \mathrm{~min}$. Within the interval $750-900 \mathrm{~min}$, time cutoff points were established at $50 \mathrm{~min}$ intervals to compare success (\% blastocyst and \% zona escape) as a function of time (Fig. 4). Each time cutoff point is inclusive, i.e., includes all embryos that had completed the third Downloaded from Bioscientifica.com at 04/26/2023 12:24:19PM 
cleavage division up to that time, and excludes slower-cleaving embryos. In all cases, cleavage was completed within one time cutoff, i.e., there was no overlap of embryos between consecutive time cutoffs. Within the time cutoff of $\leq 750 \mathrm{~min}$ for completion of $\mathrm{D} t_{8}, 92 \%$ of embryos subsequently reached the blastocyst stage and $69 \%$ escaped their zonae. As the time taken to complete the third cleavage division increased, the cumulative percentage of embryos reaching the blastocyst stage or escaping their zonae decreased (Figs 3 and 4). Although cleavage divisions within $\mathrm{D} t_{4}$ and $\mathrm{D} t_{8}$ were asynchronous, there was no correlation between the degree of asynchrony and blastocyst development.

\section{Discussion}

In clinical IVF laboratories, embryos are selected for transfer based primarily on morphology (Wolf, 1988). However, morphological criteria do not take into consideration potential aberrations that cannot be seen under a light microscope (Winston et al., 1991) but may affect embryonic potential for development in vitro or viability after embryo transfer. Using Nomarski optics and transmission electron microscopy, Sathananthan et al. (1990) found that some cultured embryos that appeared morphologically normal had multiple nuclei. Such embryos are incapable of normal development (Angell et al., 1987; Winston et al., 1991), but under a conventional light microscope, are indistinguishable from euploid embryos (Van Blerkom et al., 1984; Sathananthan et al., 1990). In addition, there may be subtle yet potentially lethal defects, such as mitochondrial damage (Dorland et al., 1994), that are not detectable at this stage (D. K. Barnett and B. D. Bavister, unpublished).

Culturing preimplantation embryos, from any stage, retards their development and alters their ability to escape from the zona pellucida (Bowman and McLaren, 1970; Harlow and Quinn, 1982; Sakkas et al., 1989; Van Soom et al., 1992; Gonzales and Bavister, 1995). Embryos that develop faster are more likely to reach the blastocyst stage or escape their zonae than are embryos that develop slowly (Bavister et al., 1983a; Plante and King, 1992; Van Soom et al., 1992; McKiernan and Bavister, 1994) and have higher pregnancy rates after embryo transfer (Hasler et al., 1987, 1995). These observations support the hypothesis that time can be used as a noninvasive indicator of embryo potential.

The notion that time can be used as an indicator of viability was demonstrated by McKiernan and Bavister (1994), who reported that one-cell hamster embryos that develop faster in vitro are more viable than are slower-developing embryos. In their study, although morulae and blastocysts derived from faster versus slower embryos were morphologically indistinguishable under the light microscope, twice as many fetuses were produced by the faster cleaving group after embryo transfer.

In the present study, the overall incidence of blastocyst formation and zona escape was $68 \%$ and $45 \%$, respectively. These data provide developmental endpoints but cannot predict which individual embryos will become blastocysts or escape their zonae before these endpoints are attained, and there is no assurance that the embryos reaching these stages are 'healthy'. By means of the logistic regression model, the embryos cultured from the one-cell stage that have a higher probability of reaching the blastocyst stage or undergoing zona escape can be determined, giving an early indication of the developmental potential of the embryo. The time interval best able to predict developmental potential during preimplantation development of hamster embryos in vitro is $\mathrm{D} t_{8}$. By subdividing $\mathrm{D} t_{8}$, embryos with substantially greater probability of reaching the blastocyst stage or escaping their zonae pellucidae can be selected. The ability to select noninvasively embryos with the highest probability of completing preimplantation development has considerable implications for improving the success of embryo transfers when embryo selection is made during the first few cleavage divisions, as in human IVF.

Several studies have attempted to correlate cleavage timing of human IVF embryos with development and viability, to incorporate the data into a scoring protocol for selection of embryos for transfer (Trounson et al., 1982; Cummins et al., 1986; Steer et al., 1992). However, all of these studies used periodic inspection of embryo development, an approach that is inherently flawed (Bavister, 1995). By inspecting embryos only at fixed intervals (usually 12 or $24 \mathrm{~h}$ ), the time schedule of observations is out of synchrony with embryo cleavages, and, as a result, the range of timing established for each cleavage becomes so broad as to be of little use (Bavister, 1995), and the apparent timing of successive cleavages may even overlap. For example, in one study of human IVF embryos using periodic observations, the time range for the first cleavage division was determined as $27-43 \mathrm{~h}$, for the second cleavage division $36-64 \mathrm{~h}$, and for the third cleavage division 44-73 $\mathrm{h}$ (Trounson et al., 1982). The only way to avoid this problem is to increase the frequency of observations. However, repeated disturbance of the cultured embryos for visual inspection is harmful to their development and impractical from the viewpoint of laboratory personnel. These problems are avoided by using a computer to capture digital images at frequent intervals (Gonzales and Bavister, 1995), time-lapse video (present study), or ciné recording (Grisart et al., 1994). The problems here are the high cost of the equipment and the labour intensive initial analysis of the data, but once the critical timing is established for any species and culture system (as in this study), it should be possible to use this information to select the most competent embryos in a practical or clinical setting.

In the present study, we confirmed that faster-cleaving embryos reached the blastocyst stage or escaped their zonae pellucidae at a higher frequency than did slower-cleaving embryos. In addition, we provide evidence that precise timing of embryo development can be used to predict developmental potential in vitro with an accuracy as high as $92 \%$. Finally, we identified $\mathrm{D} t_{8}$ (the developmental interval from the second to the third cleavage division) as the time interval most able to provide predictive data. We do not know why the third cell cycle is so critical for subsequent development and can serve as a predictor of the developmental capacity of embryos. Study of biochemical and molecular events taking place during this cell cycle could be informative. To test the general applicability of these observations we and other workers (Grisart et al., 1994) are collecting precise timing data on embryos from more species, including humans 
This work was supported by the National Institute of Child Health and Human Development, National Cooperative Program on NonHuman In Vitro Fertilization and Embryo Development through grant No. HD22023. The authors thank R. Foote, J. Jones and S. H. McKiernan for their editorial comments and M. Radtke for help with illustrations, and are also grateful to S. H. McKiernan for excellent technical support for this work.

\section{References}

Agresti A (1990) Categorical Data Analysis pp 85-87. John Wiley \& Sons, New York

Amso NN and Shaw RW (1993) A critical appraisal of assisted reproduction techniques Human Reproduction 8 168-174

Angell R, Sumner A, West J, Thatcher S, Glasier A and Baird D (1987) Postfertilization polyploidy in human preimplantation embryos fertilized in vitro Human Reproduction 2 721-728

Barnett DK and Bavister BD (1992) Hypotaurine requirements for in vitro development of golden hamster one-cell embryos into morulae and blastocysts, and production of term offspring from in vitro-fertilized ova Biology of Reproduction 47 297-304

Barnett DK and Bavister BD What is the relationship between the metabolism of preimplantation embryos and their development in vitro? Molecular Reproduction and Development (in press)

Bavister BD (1988a) Role of oviductal secretions in embryonic growth in vivo and in vitro Theriogenology 29 143-154

Bavister BD (1988b) A mini-chamber device for maintaining a constant carbon dioxide in air atmosphere during prolonged culture of cells on the stage of an inverted microscope In Vitro Cell Developmental Biology 24 759-763

Bavister BD (1989) A consistently successful procedure for in vitro fertilization of golden hamster eggs Gamete Research 23 139-158

Bavister BD (1995) Culture of preimplantation embryos: facts and artifacts Human Reproduction Updates 1 91-148

Bavister BD, Boatman DE, Leibfried ML, Loose M and Vernon MW (1983a) Fertilization and cleavage of rhesus monkey oocytes in vitro Biology of Reproduction 28 983-999

Bavister BD, Leibfried L and Lieberman G (1983b) Development of preimplantation embryos of the golden hamster in a defined culture medium Biology of Reproduction 28 235-247

Bernardini L, Alam V, Asch RH and Balmaceda JP (1993) Pregnancy and implantation rates in normal replacement versus stimulated cycles Human Reproduction 8 1938-1941

Bolton V, Hawes S, Taylor C and Parsons J (1989) Development of spare human preimplantation embryos in vitro: an analysis of the correlations among gross morphology, cleavage rates and development to the blastocyst Journal of In Vitro Fertilization and Embryo Transfer 6 30-35

Bowman P and McLaren A (1970) Cleavage rate of mouse embryos in vivo and in vitro Journal of Embryology and Experimental Morphology 24 203-207

Conaghan J, Hardy K, Handyside AH, Winston RML and Leese HJ (1993) Selection criteria for human embryo transfer: a comparison of pyruvate uptake and morphology Journal of Assisted Reproduction and Genetics 10 $21-29$

Cummins JM, Wilson LM, Breen TM and Hennessey JF (1986) A formula for scoring human embryo growth rates in IVF: value in predicting pregnancy and in comparison with other estimates of embryo quality Journal of In Vitro Fertilization and Embryo Transfer 3 284-295

Dorland M, Gardner DK and Trounson AO (1994) Serum in synthetic oviduct fluid causes mitochondrial degeneration in ovine embryos Journal of Reproduction and Fertility Abstract Series 13 Abstract 70

Edwards RG (1986) Causes of pregnancy loss Human Reproduction 1 $185-198$

Fishel SB, Cohen J, Fehilly C, Purdy JM, Walters ED and Edwards RG (1985) Factors influencing human embryonic development in vitro Annais of the New York Academy of Sciences 442 342-356

Gardner DK and Leese HJ (1993) Assessment of embryo metabolism and viability. In Handbook of in Vitro Fertilization pp 195-211 Eds A Trounson and DK Gardner. CRC Press, Inc. Boca Raton

Gonzales DS and Bavister BD (1995) Zona pellucida escape by hamster blastocysts in vitro is delayed and morphologically different compared with zona escape in vivo Biology of Reproduction 52 470-480
Grisart B, Massip A and Dessy F (1994) Cinematographic analysis of bovine embryo development in serum-free oviduct-conditioned medium Journal of Reproduction and Fertility $101257-264$

Handyside AH and Hunter S (1984) A rapid procedure for visualizing the inner cell mass and trophectoderm nuclei of mouse blastocysts in situ using polynucleotide-specific fluorochromes Journal of Experimental Zoology 231 429-434

Harlow GM and Quinn P (1982) Development of preimplantation mouse embryos in vivo and in vitro Australian Journal of Biological Sciences 35 $187-193$

Hasler JF (1992) Current status and potential of embryo transfer and reproductive technology in dairy cattle Journal of Dairy Science 75 2857-2879

Hasler JF, McCauley AD, Lathrop WF and Foote RH (1987) Effect of donorembryo-recipient interactions on pregnancy rate in a large-scale bovine embryo transfer program Theriogenology 27 139-168

Hasler JF, Henderson WB, Hurtgen PJ, Jin ZQ, McCauley AD, Mower SA, Neely B, Shuey LS, Stokes JE and Trimer SA (1995) Production, freezing and transfer of bovine IVF embryos and subsequent calving results Theriogenology 43 141-152

Hoppe RW and Bavister BD (1984) Evaluation of the fluorescein diacetate (FDA) vital dye viability test with hamster and bovine embryos Animal Reproduction Science 6 323-335

Hutz RJ, DeMayo FJ and Dukelow WR (1985) The use of vital dyes to assess embryonic viability in the hamster, Mesocricetus auratus Stain Technology 60 163-168

Kishi J, Noda Y, Narimoto K, Umaoka Y and Mori T (1991) Blocks to development in cultured rat 1-cell embryos is overcome using medium HECM-I Human Reproduction 6 1445-1448

Leese HJ, Hooper MAK, Edwards RG and Ashwood-Smith MJ (1986) Uptake of pyruvate by early human embryos determined by a non-invasive technique Human Reproduction 1 181-182

Lindenberg S and Hyttel P (1989) In vitro studies of the peri-implantation phases of human embryos. In Ultrastructure of Human Gametogenesis and Early Embryogenesis pp 201-211 Eds J Van Blerkom and P Motta. Kluwer Academic Publishers, Boston

Lindner GM and Wright RW Jr (1983) Bovine embryo morphology and evaluation Theriogenology 20 407-416

Lopata A and Hay DL (1989) The potential of early human embryos to form blastocysts, hatch from their zona and secrete HCG in culture Human Reproduction 4 87-94

McKiernan SH and Bavister BD (1990) Environmental variables influencing in vitro development of hamster 2-cell embryos to the blastocyst stage Biology of Reproduction 43 404-413

McKiernan SH and Bavister BD (1994) Timing of development is a critical parameter for predicting successful embryogenesis Human Reproduction 9 2123-2129

McKinnon AO and Squires EL (1988) Morphologic assessment of the equine embryo Journal of the American Veterinary Medical Association 192 401-406

Maurer RR, Onuma H and Foote RH (1970) Viability of cultured and transferred rabbit embryos Journal of Reproduction and Fertility. 21 417-422

Mohr LR and Trounson AO (1980) The use of fluorescein diacetate to assess embryo viability in the mouse Journal of Reproduction and Fertility $\mathbf{5 8}$ 189-196

Noto V, Campo R, Roziers P and Gordts S (1991) Fluorescein diacetate assessment of embryo viability after ultrarapid freezing of human multipronucleate embryos Fertility and Sterility 55 1171-1175

Orsini MW (1961) The external vaginal phenomena characterizing the stages of the estrous cycle, pregnancy, pseudopregnancy, lactation, and the anestrous hamsters, Mesocricetus auratus (Waterhouse) Proceedings of the Animal Care Panel 11 193-206

Plante $\mathrm{L}$ and King WA (1992) Effect of time to first cleavage on hatching rate of bovine embryos in vitro Theriogenology 37274 (Abstract)

Rogers PAW, Milne BJ and Trounson AO (1986) A model to show human uterine and embryo viability following ovarian stimulation for in vitro fertilization Journal of In Vitro Fertilization and Embryo Transfer 3 93-98

Sakkas D, Trounson AO and Kola I (1989) In vivo cleavage rates and viability obtained for early cleavage mouse embryos in co-culture with oviduct cells Reproduction Fertility and Development 1 127-136

Sathananthan H, Bongso A, Soon-Chye N, Ho J, Mok H and Ratham S (1990) Ultrastructure of preimplantation human embryos co-cultured with human ampullary cells Human Reproduction 5 309-318

Snedecor GW and Cochran WG (1989) Statistical Methods 9th Edn pp 89 and 223. Iowa State University Press, Ames

Downloaded from Bioscientifica.com at 04/26/2023 12:24:19PM 
Steer CV, Mills CL, Tan SL, Campbell S and Edwards RG (1992) The cumulative embryo score: a predictive embryo scoring technique to select the optimal number of embryos to transfer in an in vitro fertilization and embryo transfer program Human Reproduction 7 117-119

Tasdemir M, Tasdemir I, Kodama H, Fukuda J, Matsui T, Sekine K and Higuchi M (1993) Should we transfer bad quality embryos together with good ones to increase the number of embryos transferred and pregnancy rate in turn? Japanese Journal of Fertility and Sterility 38 9-12

Trounson AO, Mohr LR, Wood C and Leeton JF (1982) Effect of delayed insemination on in vitro fertilization, culture and transfer of human embryos Journal of Reproduction and Fertility 64 285-294

Umaoka Y, Noda Y, Nakayama T, Narimoto K, Mori T and Iritani A (1993) Development of hamster one-cell embryos recovered under different conditions to the blastocyst stage Theriogenology 39 485-498

Van Blerkom J (1989) Developmental failure in human reproduction associated with preovulatory oogenesis and preimplantation embryogenesis. In
Ultrastructure of Human Gametogenesis and Early Embryogenesis pp 125-180 Eds J Van Blerkom and P Motta. Kluwer Academic Publishers, Boston

Van Blerkom J, Henry GH and Porreco R (1984) Preimplantation human embryonic development from polypronuclear eggs after in vitro fertilization Fertility and Sterility $\mathbf{4 1}$ 686-696

Van Soom A, Van Vlaenderen I, Mahmoudzadeh AR, Deluyker H and de Kruif A (1992) Compaction rate of in vitro fertilized bovine embryos related to the interval from insemination to first cleavage Theriogenology $\mathbf{3 8}$ 905-919

Winston NJ, Braude PR, Pickering SJ, George MA, Cant A, Currie J and Johnson MH (1991) The incidence of abnormal morphology and nucleocytoplasmic ratios in 2-, 3-, and 5-day human pre-embryos Human Reproduction $617-24$

Wolf DP (1988) Analysis of embryonic development. In In Vitro Fertilization and Embryo Transfer pp 137-145 Eds DP Wolf, BD Bavister, M Gerrity and GS Kopf. Plenum Press, New York 